\title{
ANALISIS SWITCHING INTENTION PENGGUNA JASA LAYANAN RUMAH KOS DI SIWALANKERTO: PERSPEKTIF KUALITAS LAYANAN DAN KEPUASAN PELANGGAN
}

\author{
Liza Agustina Maureen Nelloh \\ Program Studi Manajemen, Fakultas Ekonomi, Universitas Pelita Harapan Surabaya \\ Email: liza.nelloh@gmail.com \\ Carolina Chandra Purwanto Liem \\ Alumnus, Program Studi Manajemen, Universitas Pelita Harapan Surabaya \\ Email: carolina.chandra90@gmail.com
}

\begin{abstract}
Abstrak: Peningkatan beberapa universitas baru di Surabaya memicu persaingan yang ketat di bidang jasa khsususnya jasa layanan rumah kos. Penelitian ini ingin melihat switching intention ditinjau dari sudut kualitas layanan dan kepuasan pelanggan yang merupakan sebagian kecil dari integrasi model dari push, pull, dan mooring factors pengguna rumah kos di Siwalankerto. Penelitian ini menggunakan PLS (Partial Least Sqaure) untuk menguji hipotesis penelitian. Hasil penelitian ini menunjukan bahwa kualitas layanan berpengaruh signifikan dan positif terhadap kepuasan, serta memiliki pengaruh yang negatif signifikan terhadap switching intention. Namun, kepuasan pelanggan tidak mampu memberikan pengaruh yang signifikan pada switching intention. Implikasi manajerial dalam penelitian ini sebaiknya menigkatkan kualitas layanan untuk meningkatkan kualitas layanan dan menurunkan switching intention pengguna jasa layanan rumah kos di Siwalankerto dan secara umum di Surabaya.
\end{abstract}

Kata kunci: switching intention, kualitas layanan, kepuasan pelanggan, rumah kos, Siwalankerto.

\begin{abstract}
The Increasing number of new universities nowadays in Surabaya led to higher competition in services especially in boarding house services. This study wanted to see the switching intention from the point of service quality and customer satisfaction which is a fraction of the integration model of push, pull, and mooring factors in the sector of boarding house users. To test the hypothesis, the researcher use PLS (Partial Least Sqaure). The results of this study indicate that the service quality have a significant and positive impact on customer satisfaction, as well as having a significant negative impact on switching intention. However, customer satisfaction can not have a significant effect on switching intention. Managerial implications of this research would be to improve service quality and lower the user's intention to switch to another houses and it would applied in service boarding house for both Siwalankerto area and as general in Surabaya.
\end{abstract}

Kaywords: switching intention, service quality, customer satisfaction, boarding house, Siwalankerto.

\section{PENDAHULUAN}

Surabaya sebagai salah satu kota pendidikan telah menyediakan sarana dan prasarana pendidikan yang memadai, meliputi tingkat pendidikan dasar, menengah dan pendidikan tinggi (www.surabaya.go.id). Dalam website resmi pemerintah kota Surabaya tercatat 41 perguruan tinggi swasta, dimana salah satu perguruan tinggi swasta ternama di Surabaya adalah Universitas Kristen Petra (UK Petra) dan Universitas Pelita Harapan Surabaya (UPHS). Melihat partumbuhan jumlah mahasiswa UK Petra dan UPHS yang semakin meningkat, diduga menjadi salah satu indikator dari berkembangnya rumah kos di Siwalankerto, dimana kebutuhan tempat tinggal sangat penting bagi para mahasiswa, khususnya yang berasal dari luar Surabaya.
Saat ini UK Petra memiliki mahasiswa berjumlah lebih dari 15.500 orang (www.petra.ac.id). Dengan meningkatnya mahasiswa UK Petra setiap tahunnya, diduga memicu terjadinya persaingan di rumah kos Siwalankerto. Perkembangan rumah kos di Siwalankerto dari tahun ke tahun memicu peningkatan jumlah rumah kos yang lebih eksklusif dengan tujuan untuk memenuhi permintaan dari pelanggan, dimana menurut berbagai sumber di internet dan koran, saat ini banyak rumah kos yang mengiklankan tempatnya dengan berfokus pada bangunan mewah dan fasilitas yang lengkap serupa dengan fasilitas yang ada pada hotel berbintang. Faktor-faktor tersebut menyebabkan terjadinya persaingan yang ketat pada bisnis jasa rumah kos. Hal ini membuat para pemilik rumah kos bersaing untuk memberikan jasa yang terbaik supaya para peng- 
gunanya tidak pindah ke rumah kos yang lain. Kualitas layanan akan mempengaruhi kepuasan pelanggan, dimana semakin baik kualitas layanan yang diberikan, maka semakin tinggi pula tingkat kepuasan dari pelanggan. Servqual menghubungkan pandangan dari pelanggan dan penyedia jasa mengenai kualitas pelayanan, serta merupakan dasar yang baik dalam memahami, mengukur dan memperbaiki kualitas pelayanan.

Sebaliknya, apabila tingkat kualitas layanan dan kepuasan pelanggan rendah, maka tingkat switching intention akan meningkat. Perpindahan merek atau perilaku pindah merupakan konsep yang bertolak belakang dengan loyalitas pelanggan. Oleh karena itu, pemilik kos sebaiknya mengurangi tingkat perpindahan pengguna rumah kosnya. Penelitian mengenai perpindahan pelanggan telah banyak diteliti sebelumnya diberbagai sektor, contohnya sektor jasa (Bansal, Taylor, \& James, 2005) dan sektor UKM (Haryanto, 2007), serta sektor UKM pada bengkel mobil (Listyarini, Haryanto, \& Siahaan, 2009). Hasil dalam penelitian tersebut termasuk beragam, yang pada intinya bahwa faktor push yang terdiri dari beberapa faktor seperti kualitas layanan, persepsi nilai, komitmen, kepuasan dan lainnya. Beberapa hal tersebut mengindikasikan apabila tingkatnya rendah, maka intensi untuk berpindah akan tinggi. Oleh karena itu, faktor push sebaiknya ditingkatkan.

Penelitian sebelumnya oleh Bansal et. al. (2005) mengkaji faktor push yang didalamnya terdapat kualitas layanan dan kepuasan berpengaruh pada intensi untuk berpindah. Penelitian mengenai penerapan sebagian model penelitian dari Bansal tersebut belum pernah diteliti di sektor UKM, khususnya rumah kos di Surabaya.

\section{TEORI PENUNJANG}

\section{Konsep Kualitas Layanan}

Kualitas layanan merupakan merupakan keseluruhan berbagai ciri dan karakteristik dari suatu produk atau jasa dalam hal kemampuan untuk memenuhi berbagai kebutuhan yang telah ditentukan atau yang bersifat laten (Parasuraman et.al., 1985).

Metode Servqual adalah metode yang sering digunakan untuk mengukur kualitas layanan. Dalam metode servqual terdapat lima dimensi servqual yang paling menentukan kualitas pelayanan (Parasuraman et all., 1988 dalam Killa, 2011) yaitu:

1. Tangibles: Fasilitas fisik, peralatan dan penampilan personel.

2. Emphaty: Kepedulian dan perhatian perusahaan kepada pelanggan.
3. Responsiveness: Keinginan perusahaan untuk membantu pelanggan dan menjanjikan jasa yang tepat.

4. Reliability: Kemampuan perusahaan dalam menepati janji dan dapat diandalkan.

5. Assurance: Pengetahuan dan keramahtamahan para personel dan kemampuan mereka menciptakan opini untuk dapat dipercaya pelanggan.

\section{Konsep Kepuasan Pelanggan}

Kotler (2000) menjelaskan kepuasan pelanggan sebagai hasil yang dirasakan oleh pembeli yang mengalami kinerja sebuah perusahaan yang sesuai dengan harapannya. Kepuasan dan ketidakpuasan merupakan konsep penting yang perlu dipahami karena dapat mempengaruhi perilaku konsumen selanjutnya. Kepuasan pelanggan adalah suatu tingkatan dimana kebutuhan, keinginan dan harapan dari pelanggan dapat terpenuhi yang akan mengakibatkan terjadinya pembelian ulang atau kesetiaan yang berlanjut (Band, 1991 dalam Musanto, 2004).

Philip Kotler (1997) mengatakan bahwa ada empat metode yang dilakukan oleh perusahaan untuk mengetahui tingkat kepuasan konsumen yaitu:

1. Sistem keluhan dan saran

Untuk mengidentifikasikan masalah maka perusahaan harus mengumpulkan informasi langsung dari konsumen dengan cara menyediakan kotak saran. Informasi yang terkumpul untuk memberikan masukan bagi perusahaan.

2. Survei kepuasan konsumen

Survei kepuasan konsumen dapat dilakukan dengan cara survei melalui pos surat, telephone, maupun wawancara pribadi. Dengan metode ini perusahaan dapat menciptakan komunikasi 2 arah dan menunjukkan perhatiannya kepada konsumen.

3. Ghost Shopping

Metode ini digunakan untuk mengetahui kekuatan dan kelemahan perusahaan pesaing dan membandingkannya dengan perusahaan yang bersangkutan.

4. Analisis Kehilangan Konsumen

Tingkat kehilangan konsumen menunjukkan kegagalan perusahaan dalam memuaskan konsumennya. Perusahaan seharusnya menganalisa dan memahami penyebab konsumen berhenti dalam mengkonsumsi/menggunakan suatu produk.

Menurut Tjiptono (1997), kepuasan atau ketidakpuasan pelanggan adalah respon pelanggan terhadap evolusi ketidaksesuaian (discinfirmation) yang dirasakan antara harapan sebelumnya dan kinerja aktual produk yang dirasakan bahwa pada 
persaingan yang semakin ketat ini, semakin banyak produsen yang terlibat dalam pemenuhan kebutuhan dan keinginan konsumen sehingga hal ini menyebabkan setiap badan usaha harus menempatkan orientasi pada kepuasan pelanggan sebagai tujuan utama, antara lain dengan semakin banyaknya badan usaha yang menyatakan komitmen terhadap kepuasan pelanggan dalam pernyataan misi dan iklan.

\section{Konsep Switching Intention}

Bansal, et. al. (2005) menjelaskan intensi berpindah (switching intention) sebagai tingkat kemungkinan atau kepastian bahwa pelanggan akan berpindah dari penyedia jasa saat ini kepada penyedia jasa baru. Banyak studi perpindahan pelanggan menjelaskan bahwa faktor-faktor penentu perpindahan, seperti kualitas, kepuasan, biaya berpindah, dan ketertarikan atas alternatif, telah dimodelkan dengan intensi berpindah. Bansal et al. (2005) mengatakan bahwa beberapa faktor yang mempengaruhi perpindahan pelanggan dikelompokkan ke dalam tiga kategori, yaitu efek pendorong (push effects), efek penarik (pull effects), dan efek penambat (mooring effects).

Roos, Edvardsson dan Gustafsson (2004) membagi migrasi pelanggan menjadi dua yakni migrasi internal dan eksternal. Dimana migrasi internal adalah migrasi pelanggan yang terjadi tetapi masih dalam lingkup perusahaan yang sama. Jenis migrasi ini secara garis besar masih menguntungkan perusahaan karena masih dalam perusahaan yang sama meskipun dalam unit yang berbeda. Sedangkan migrasi eksternal adalah migrasi pelanggan ke penyedia jasa alternatif diluar perusahaan.

Penelitian tentang perpindahan pelanggan telah banyak diteliti sebelumnya diberbagai sektor, contohnya sektor jasa (Bansal, Taylor, \& James, 2005) dan sektor UKM (Haryanto, 2007), serta sektor UKM pada bengkel mobil (Listyarini, Haryanto, \& Siahaan, 2009). Hasil dalam penelitian tersebut termasuk beragam, yang pada intinya bahwa faktor push yang terdiri dari beberapa faktor seperti kualitas layanan, persepsi nilai, komitmen, kepuasan pelanggan dan lainnya. Beberapa hal tersebut mengindikasikan apabila tingkatnya rendah, maka intensi untuk berpindah akan tinggi. Oleh karena itu, faktor push sebaiknya ditingkatkan.

Menurut Haryanto (2007), ada tiga jenis intensi, yaitu sebagai berikut:

1) Intensi sebagai harapan, yaitu harapan-harapan yang timbul dalam diri seseorang untuk melakukan sesuatu.

2) Intensi sebagai keinginan, yaitu keinginan dalam diri seseorang untuk melakukan sesuatu.
3) Intensi sebagai rencana, yaitu rencana seseorang untuk melakukan sesuatu.

\section{Hubungan Antara Kualitas Layanan dan Kepuas- an Pelanggan}

Untuk menghasilkan suatu kepuasan pelanggan, maka perusahaan membutuhkan kualitas layanan yang baik pula. Atmawati dan Wahyuddin (2005) menemukan bahwa kepuasan pelanggan ditentukan oleh persepsi pelanggan mengenai kualitas jasa yang berfokus pada lima dimensi kualitas jasa, yaitu: tangibles, emphathy, responsiveness, reliability, dan assurance. Hal ini menunjukkan bahwa ketika tingkat tangibles, emphaty, responsiveness, reliability, dan assurance yang dirasakan lebih tinggi, maka akan menyebabkan kepuasan pembeli yang lebih besar.

\section{Hubungan Antara Kualitas Layanan dan Swit- ching Intention}

Kualitas layanan tidak hanya mempengaruhi kepuasan atau ketidakpuasan konsumen, namun juga berpengaruh pada beberapa respon perilaku (Malik \& Naeem, 2011). Hasil penelitian tersebut menjelaskan bahwa kualitas layanan dapat berpengaruh pada switching intention.

Menurut Berry, et. al. (1988) dalam Yuliana dan Mustikawati (2007), kualitas jasa menjadi senjata kompetitif yang paling kuat oleh banyak organisasi dalam hal pelayanan, dimana upaya ini dapat meminimalkan pelanggan untuk berpindah dan mencari penyedia jasa baru yang lebih baik. Dalam penelitian ini, apabila kualitas layanan rumah kos tidak baik, maka kecenderungan pelanggan atau pengguna rumah kos menjadi tidak puas dan cenderung atau memiliki niat untuk pindah rumah kos.

\section{Hubungan Antara Kepuasan Pelanggan dan Swit- ching Intention}

Switching Intention yang berasal dari switching behavior merupakan sisi yang berlawanan dengan keputusan untuk membeli atau kesetiaan merek.

Bansal et.al. (2005) mengungkapkan bahwa kepuasan pelanggan berpengaruh negatif pada switching intention. Secara tidak langsung, ketika konsumen tidak puas, maka konsumen akan cenderung berpindah. Selain itu, Wibowo (2008) menjelaskan beberapa faktor penentu perpindahan, seperti kualitas dan kepuasan, telah dimodelkan dengan switching intention. Kepuasan pelanggan mencakup upaya-upaya dalam memenuhi bahkan melampaui harapan konsumen. 


\section{Kerangka Berpikir}

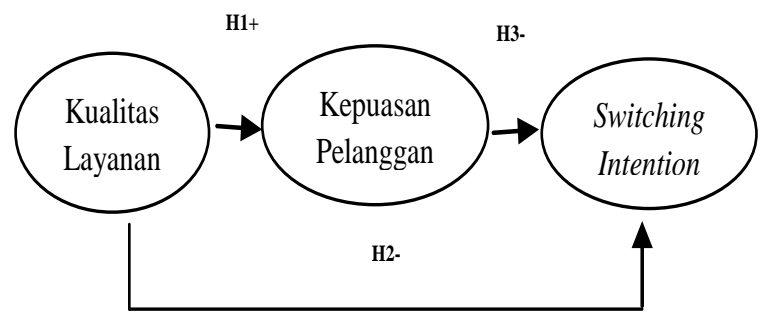

Gambar 1. Kerangka Berpikir

\section{Hipotesis}

Berdasarkan teori di atas, penulis menyusun hipotesis sebagai berikut:

1. Kualitas layanan berpengaruh positif terhadap kepuasan mahasiswa pengguna rumah kos di Siwalankerto Surabaya (H1).

2. Kualitas layanan berpengaruh negatif terhadap switching intention mahasiswa pengguna rumah kos di Siwalankerto Surabaya (H2).

3. Kepuasan pelanggan berpengaruh negatif terhadap switching intention mahasiswa pengguna rumah kos di Siwalankerto Surabaya (H3).

\section{METODE PENELITIAN}

\section{Jenis Penelitian, Populasi dan Sampel}

Penelitian ini menggunakan pendekatan kuantitatif yang bertujuan untuk menguji pengaruh beberapa faktor (kualitas layanan, kepuasan pelanggan dan switching intention). Penelitian ini merupakan penelitian kausal karena penelitian ini digunakan untuk mengembangkan model penelitian yang bertujuan untuk menguji hipotesis penelitian yang telah ditentukan.

Populasi penelitian ini adalah mahasiswa pengguna rumah kos di Siwalankerto Surabaya, dimana penulis akan membagikan kuesioner di rumah-rumah kos Siwalankerto, UK. Petra, dan UPH Surabaya.

Metode sampel yang digunakan adalah non probability sampling yaitu pemilihan sampel berdasarkan pada pertimbangan pribadi (Supramono \& Haryanto, 2005). Berdasarkan penjelasan tersebut maka penelitian ini menggunakan non probability sampling dengan jenis purposive sampling yaitu peneliti memilih sampel berdasarkan kriteria tertentu untuk memilih sampel yang diharapkan memiliki informasi yang akurat (Supramono \& Haryanto, 2005). Dalam penelitian ini penulis memfokuskan pada mahasiswa pengguna rumah kos yang dalam kurun waktu setahun memiliki frekuensi pindah rumah kos minimal satu kali.

\section{Jenis dan Sumber Data}

Jenis data yang digunakan dalam penelitian ini yaitu:

1) Data primer, yaitu data yang diperoleh melalui penyebaran kuesioner yang terbatas pada mahasiswa pengguna rumah kos di Siwalankerto Surabaya dan pernah melakukan pindah rumah kos minimal satu kali dalam kurun waktu satu tahun terakhir. Metode survei akan dilakukan secara langsung kepada mahasiswa pengguna rumah kos di Siwalankerto yang sudah pernah melakukan pindah rumah kos dan langsung dimintai kesediaannya untuk mengisi kuesioner.

2) Data Sekunder, yaitu data yang diperoleh dari tinjauan kepustakaan melalui literatur, jurnaljurnal, dan situs internet yang dapat memberikan informasi yang berkaitan dengan kualitas layanan, kepuasan pelanggan, dan switching intention yang sesuai dengan masalah penelitian.

\section{Definisi Operasional Variabel}

1. Kualitas layanan adalah keseluruhan berbagai ciri dan karakteristik dari suatu jasa rumah kos dalam hal kemampuan untuk memenuhi berbagai kebutuhan yang telah ditentukan atau yang bersifat laten. Indikator empirik:

Tangibles:

a. Memiliki tempat parkir yang luas

b. Memiliki fasilitas yang lengkap

c. Memiliki kamar yang luas

d. Memiliki bangunan kos yang modern

e. Memiliki pegawai yang berpenampilan bersih

f. Memiliki pegawai yang ramah

g. Memiliki pegawai yang memperhatikan keadaan

h. Memiliki pegawai yang sopan dalam melayani

i. Memiliki pegawai yang menanggapi kebutuhan dengan cepat

j. Memiliki pegawai yang menindaklanjuti keluhan dengan cepat

k. Memiliki pegawai yang dapat diandalkan

1. Terjaga kebersihannya

m. Memberikan janji-janji yang selalu ditepati

n. Memiliki keamanan yang terpercaya

2. Kepuasan pelanggan adalah hasil yang dirasakan oleh pengguna rumah kos yang mengalami kinerja sebuah rumah kos yang sesuai dengan harapannya. Indikator empirik:

a. Rumah kos di Siwalankerto sesuai harapan pelanggan.

b. Rumah kos di Siwalankerto sesuai keinginan pelanggan.

c. Rumah kos di Siwalankerto sesuai kebutuhan. 
3. Switching Intention adalah tingkat kemungkinan atau kepastian bahwa pengguna rumah kos akan berpindah dari penyedia jasa rumah kos saat ini kepada penyedia jasa rumah kos yang baru. Indikator empirik:

a. Memiliki harapan yang kuat untuk pindah rumah kos yang lain

b. Ingin berpindah rumah kos yang lain

c. Memiliki rencana yang matang untuk berpindah rumah kos yang lain

\section{TEKNIK ANALISIS DATA}

\section{Statistik Deskriptif}

Dalam penelitian ini penulis melakukan perhitungan distribusi frekuensi dan mean (nilai rata-rata) untuk memberikan gambaran atau deskripsi dari data yang diperoleh.

\section{Analisis Path Dengan Menggunakan Permodelan SEM (Structural Equation Modeling)}

Menurut Basuki (2006) prinsip structural equation model merupakan pendekatan terintegrasi dari confirmatory factor analysis dan path analysis (analisis jalur). Analisis jalur mempelajari apakah hubungan yang terjadi disebabkan oleh pengaruh langsung dan tidak langsung dari variabel independen terhadap variabel dependen, mempelajari ketergantungan sejumlah variable dalam suatu model (model kausal), menganalisis hubungan antar variabel dari model kausal yang telah dirumuskan oleh peneliti atas dasar pertimbangan teoritis, serta menguji seperangkat hipotesis kausal dan menginterpretasikan hubungan tersebut (langsung atau tidak langsung).

\section{Partial Least Square (PLS)}

Partial least square merupakan pengembangan dari Structural Equation Model berbasis varians yang lebih berorientasi pada prediksi, dan untuk menjelaskan ada atau tidaknya hubungan antara variabel laten. Menurut Ghozali (2006) menjelaskan bahwa jika model struktural dan model pengukuran yang dihipotesiskan benar dalam artian menjelaskan covariance semua indikator dan kondisi data serta sample size terpenuhi, maka covariance based SEM memberikan estimasi optimal dari parameter model.

\section{ANALISIS DAN PEMBAHASAN}

\section{Analisis Profil Responden}

Hasil penelitian ini didapatkan bahwa dari 155 jumlah repsonden, terdapat $72 \%$ responden perem- puan dan 28\% responden pria. Responden yang menganggarkan Rp. 500.000 - Rp. 1.000 .000 berada pada tingkat teratas untuk anggaran rumah kos per bulan, serta frekuensi pindah responden terwakilkan $51 \%$ yang telah pindah lebih atau sama dengan 3 kali per tahunnya.

\section{Analisis Partial Least Square}

\section{Uji Validitas dan Reliabilitas}

Sebelum pengujian structural model, penelitian sebaiknya mencapai pengujian validitas dan reliabilitas (Roostika, 2012). Melalui analisis PLS, pengujian validitas dan reliabilitas dilakukan dengan pengujian measurement model (outer model) yang didalamnya terdapat internal composite reliability (ICR), average variance extracted (AVE) and discriminant validity (Chin, 1988). Kemudian, Roostika (2011) dan menyimplkan bahwa estimasi pengukuran yang signifikan yaitu pada pengujian bootstrapped 500 samples. Hasil pengujian validitas dan reliabilitas dapat dilihat melalui Tabel 1 dan Tabel 2 .

Tabel 1 menunjukkan bahwa semua kriteria statistic memenuhi persyaratan yaitu ICR > 0.6 (Fornell dan Larcker, 1998), dan AVE > 0.5 (Ghozali, 2006)

Tabel. 1. Pengujian ICR dan AVE

\begin{tabular}{lll}
\hline Variabel & ICR & AVE \\
\hline Kualitas Layanan & 0.973643 & 0.725722 \\
Kepuasan Pelanggan & 0.950082 & 0.863872 \\
Switching Intention & 0.972975 & 0.923094 \\
\hline
\end{tabular}

Sumber: Data diolah (2012)

Untuk pengujian discriminant validity, Ghozali (2006) mengatakan bahwa pengujian ini dinilai berdasarkan cross loading pengukuran dengan konstruk. Jlka korelasi kosntruk dengan item pengukuran lebih besar daripada ukuran kosntruk lainnya, maka hal ini menunjukkan bahwa kosntruk laten memprediksi ukuran pada blok tertentu lebih baik daripada ukuran blok lainnya. Selanjutnya dikatakan bahwa untuk menguji discriminant validity adalah membandingkan nilai square root of average variance extracted setiap kosntruk dengan korelasi antara konstuk satu dan kosntruk lainnya dalam konsep. Ghozali (2006) melanjutkan, bahwa apablika nilai akar AVE setiap konstruk lebih besar dari pada nilai korelasi antara konstruk dengan konstruk lainnya dalam model, maka dikatakan memiliki discriminant validity yang baik. 
Tabel 2. Cross Loadings

\begin{tabular}{llll}
\hline Indikator & $\begin{array}{l}\text { Kepuasan } \\
\text { Pelanggan }\end{array}$ & $\begin{array}{l}\text { Kualitas } \\
\text { Layanan }\end{array}$ & $\begin{array}{l}\text { Switching } \\
\text { Intention }\end{array}$ \\
\hline x1 & 0.649414 & 0.822833 & -0.594426 \\
x10 & 0.776487 & 0.887565 & -0.740203 \\
x11 & 0.778938 & 0.837663 & -0.691719 \\
x12 & 0.674216 & 0.84375 & -0.693821 \\
x13 & 0.727599 & 0.854928 & -0.742492 \\
x14 & 0.772219 & 0.8537 & -0.728112 \\
x2 & 0.696882 & 0.882214 & -0.686158 \\
x3 & 0.708332 & 0.877143 & -0.76734 \\
x4 & 0.749609 & 0.895312 & -0.710014 \\
x5 & 0.586732 & 0.713309 & -0.523031 \\
x6 & 0.688097 & 0.83669 & -0.716128 \\
x7 & 0.715773 & 0.833488 & -0.591889 \\
x8 & 0.72032 & 0.873085 & -0.72212 \\
x9 & 0.7804 & 0.898263 & -0.756811 \\
y1 & 0.939743 & 0.78062 & -0.69919 \\
y2 & 0.940957 & 0.816056 & -0.709974 \\
y3 & 0.907248 & 0.753164 & -0.663876 \\
y4 & -0.748292 & -0.794392 & 0.968497 \\
y5 & -0.702121 & -0.783205 & 0.969823 \\
y6 & -0.692597 & -0.770081 & 0.943789 \\
\hline S4m
\end{tabular}

Sumber: Data diolah (2012)
Pada Tabel 2 dapat disimpulkan bahwa variabel kualitas layanan dengan indikatornya (x1-x14) lebih tinggi dibandingkan korelasi x1-x14 dengan variabel lainnya (kepuasan pelanggan dan switching intention). Hal ini berlaku juga sebaliknya yaitu variabel kepuasan layanan dengan indikatornya (y1, y2, dan y3) lebih tinggi dibandingkan dengan korelasi antara y1, y2, y3 dengan variabel lainnya (kualitas layanan dan switching intention). Kemudian, untuk variabel switching intention, terbukti bahwa korelasi antara variabel tersebut dengan indikatornya (y4, y5, dan y6) lebih besar dibandingkan dengan korelasi y4, y5, dan y6 dengan indikator lain seperti kualitas layanan dan kepuasan pelanggan. Hal ini membuktikan bahwa variabel laten (kualitas layanan, kepuasan pelanggan, dan switching intention) memprediksi indikator pada blok masing-masing variabel dibandingkan dengan blok lainnya. Kemudian, dari pengujian ICR, AVE, dan cross loadings diatas dapat disimpulkan bahwa semua persyaratan statistic untuk pengujian validitas dan reliabilitas dapat diterima dengan baik.

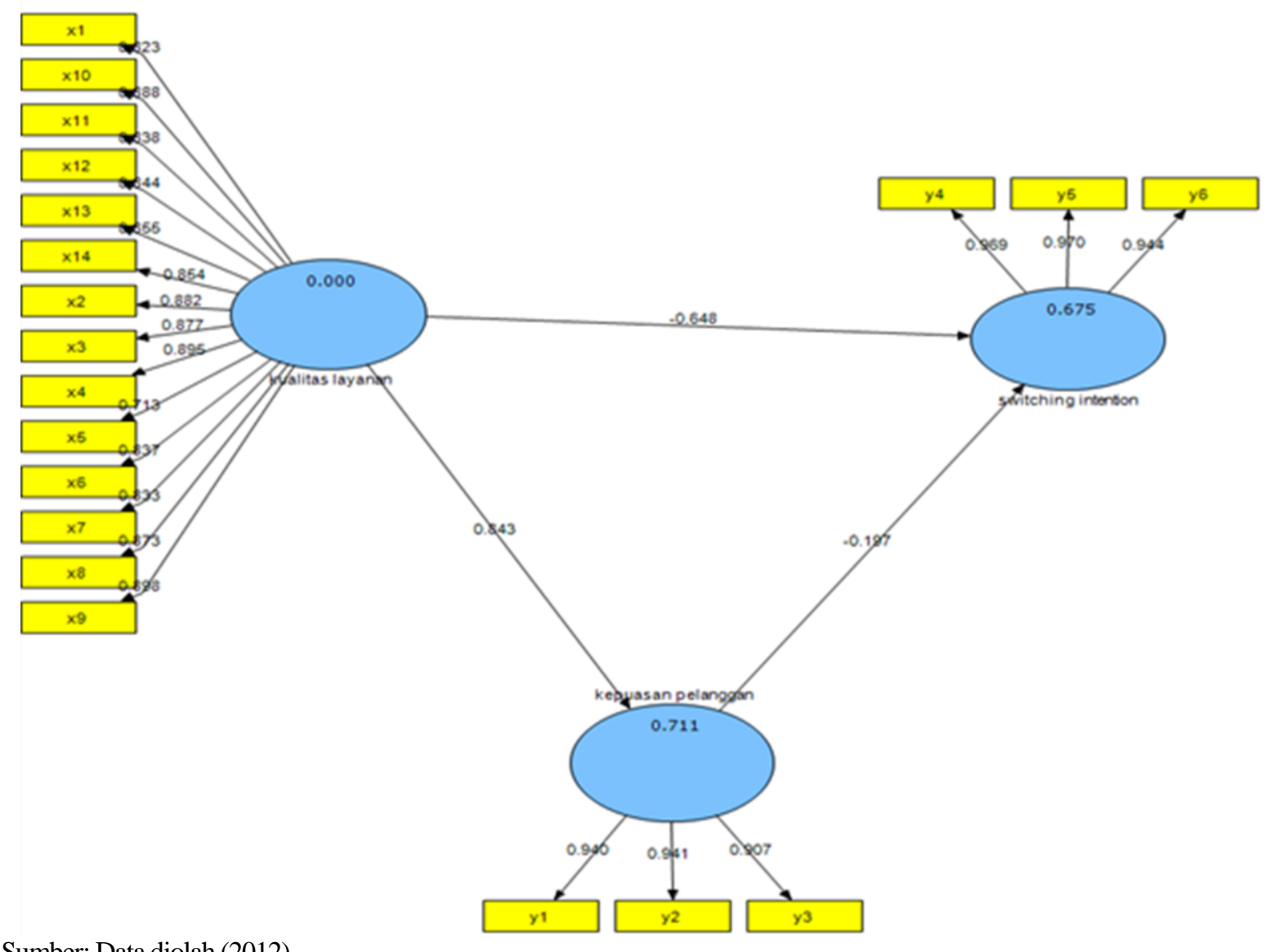

Sumber: Data diolah (2012)

Gambar 1. Model Struktural (Inner Model) 


\section{Uji HIpotesis}

Dalam PLS, pengujian hipotesis dapat dilakukan dengan menguji model structural (inner model) yang terdiri dari $\mathrm{R}^{2}$, path coefficients, dan $t$-statistics (Chin, 1998). Dalam penelitian ini dapat dilihat melalui Gambar 2 path analysis yang didalamnya terdapat $\mathrm{R}^{2}$ dan path coefficient untuk pengujian inner model. Gambar 2 menyimpulkan bahwa path coefficient untuk pengaruh kualitas layanan terhadap kepuasan pelanggan sebesar 0.843 , sedangkan pengaruhnya ke switching intention sebesar -0.648. Kemudian, pengaruh kepuasan pelanggan terhadap switching intention sebesar -0.197. Hal ini dapat dilihat juga melalui Tabel 3. Untuk pengujian $\mathrm{R}^{2}$, dengan melihat gambar 2 dapat disimpulkan bahwa kepuasan pelanggan memiliki $\mathrm{R}^{2}$ sebesar 0.7111148 , dan switching intention memiliki $\mathrm{R}^{2}$ sebesar 0.674796 .

Tabel 3. Uji Hipotesis

\begin{tabular}{lll}
\hline Hipotesis & $\begin{array}{l}\text { Original } \\
\text { Sample } \\
\text { Estimate }\end{array}$ & T-Statistics \\
\hline $\begin{array}{l}\text { kepuasan pelanggan -> } \\
\text { switching intention } \\
\text { kualitas layanan -> } \\
\begin{array}{l}\text { kepuasan pelanggan } \\
\text { kualitas layanan -> } \\
\text { switching intention }\end{array}\end{array}$ & -0.196973 & 1.562611 \\
\hline
\end{tabular}

Sumber: Data diolah (2012)

Berdasarkan Tabel 3 dan Gambar 2 dapat dilihat bahwa hipotesis 1 , didukung data dengan koefisien parameter pengaruh kualitas layanan adalah 0.843296 dengan tingkat signifikan pada 0.05 dan T-statistic $>1.96$ (Ghozali, 2006). Jadi dapat disimpulkan bahwa kualitas layanan berpengaruh positif terhadap kepuasan pelanggan dalam hal ini pengguna rumah kos di Siwalankerto dengan R-square sebesar 0.711 atau variabilitas kepuasan pelanggan dapat dijelaskan oleh kualitas layanan sebesar $71.11 \%$.

Hal ini sesuai dukungan dukungan hasil penelitian sebelumnya dari Atmawati dan Wahyudin (2005).

Pada hipotesis 2, dapat disimpulkan bahwa kualitas layanan berpengaruh negatif pada switching intention didukung data. Hal ini dibuktikan dengan koefisien parameter -0.648504 pada tingkat 0.05 dengan nilai t-statistic sebesar 5.229771 dengan Rsquare sebesar 0.674796 atau variabilitas switching intention dapat dijelaskan oleh kualitas layanan sebesar $67.47 \%$. Hasil uji hipotesis ini sesuai dengan hasil penelitian sebelumnya (seperti pada Gambar 2).
Menurut Berry, et. al. (1988) dalam Yuliana dan Mustikawati (2007). Selanjutnya hipotesis 3, kepuasan pelanggan berpengaruh negatif terhadap switching intention mahasiswa pengguna rumah kos di Siwalankerto Surabaya $(\mathrm{H} 2)$ terbukti tidak didukung data dengan nilai t-statistic <1.96 yang membuktikan bahwa koefisien parameter -0.196973 tidak berada pada tingkat signifikan 0.05 . Oleh karena itu, hal ini membuktikan bahwa kepuasan pelanggan tidak signifikan berpengaruh pada switching intention, namun hal ini juga dapat diartikan arah pengaruhnya tetap pada hubungan yang berlawanan yaitu dengan koefisien parameter yang negatif. Oleh karena tidak signifikannya pengaruh kepuasan pelanggan terhadap switching intention, maka total $67.47 \%$ hanya mampu dijelaskan oleh kualitas layanan dan bukan pada kepuasan pelanggan.

Ditolaknya H3 dapat member kesimpulan menolak teori yang mengatakan bahwa kepuasan pelanggan akan berpengaruh secara signifikan dan negatif terhadap switching intention (Bansal et.al 2005, Kim, Park, \& Jeong, 2004, Szymanski \& Henard, 2001). Hal ini berarti, kepuasan pelanggan di rumah kos Siwalankerto tidak mampu untuk memberikan pengaruh yang signifikan terhadap intensi untuk berpindah kos di Siwalankerto. Hal tersebut disinyalir karena sebagian besar responden (51\%) merupakan pengguna yang berasal dari middle up income atau higher income yang memiliki kecenderungan untuk tidak setia (Cooil et.al.,2007). Hal ini berarti ditolaknya H3 disinyalir karena responden yang kebanyakan higher income.

\section{KESIMPULAN DAN SARAN}

\section{Kesimpulan}

Terdapat beberapa kesimpulan dalam penelitian ini, yaitu sebagai berikut:

1. Kebanyakan responden terdiri dari responden wanita yaitu $72 \%$ dan $51 \%$ diantaranya memiliki anggaran rumah kos Rp. 500.000 - Rp. 1.000 .000 yang dapat disimpulkan yaitu responen berasal dari keluarga middle up income.

2. Semua kriteria pengujian validitas dan reliabilitas dalam penelitian ini sesuai dengan persyaratan statistik secara umum.

3. Kualitas layanan terbukti berpengaruh positif terhadap kepuasan pelanggan rumah kos di Siwalankerto Surabaya.

4. Kualitas layanan terbukti berpengaruh negatif pada switching intention pelanggan rumah kos di Siwalankerto Surabaya. 
5. Kepuasan pelanggan tidak terbukti berpengaruh signifikan terhadap switching intention pelanggan rumah kos di Siwalankerto Surabaya, namun arah pengaruhnya tetap pada hubungan yang berlawanan.

6. Secara keseluruhan, peneliti menyimpulkan bahwa tingkat switching intention di Siwalankerto akan rendah apabila dipengaruhi oleh kualitas layanan yang memadai. Hal tersebut apabila dimaksimalkan, maka disinyalir tingkat kepuasan akan semakin meningkat dan switching intention di Siwalankerto juga semakin menurun. Namun, di sektor jasa khususnya di rumah kos, kepuasan pelanggan tidak mampu menurunkan tingkat switching intention.

\section{Saran}

Berdasarkan hasil pemaparan dalam penelitian ini, maka peneliti mengungkapkan beberapa saran dari sisi manajerial atau pemilik rumah kos secara umum, yaitu sebagai berikut:

1. Kualitas layanan sebaiknya ditingkatkan dengan memperhatikan beberapa hal yaitu tangible seperti tempat parkir yang luas, rumah kos sebaiknya memiliki fasilitas yang lengkap, memiliki kamar yang luas, memiliki bangunan kos yang modern dan Memiliki pegawai yang berpenampilan bersih. Hal ini dibuktikan dengan peningkatan menyeluruh dalam bidang fasilitas fisik rumah kos untuk memberikan persepsi yang positif mengenai kualitas layanan dengan target market medium high customers.

2. Dimensi kualitas layanan yang kedua dan sebaiknya diperhatikan adalah emphaty yaitu memiliki pegawai yang ramah, memiliki pegawai yang memperhatikan keadaan, memiliki pegawai yang sopan dalam melayani. Schiffman dan Kanuk (2010) menyimpulkan bahwa para medium high lebih loyal pada suatu jasa yang menawarkan kenyamanan termasuk memberikan empati pada kebutuhan pengguna rumah kos.

3. Kemudian dimensi berikut adalah responsiveness yaitu memiliki pegawai yang menanggapi kebutuhan dengan cepat, memiliki pegawai yang menindaklanjuti keluhan dengan cepat. Sesuai pemaparan Schiffman dan Kanuk (2010), pelanggan middle up yang lebih suka kenyamanan akan merasa nyaman apabila kebutuhannya tetap ditanggapi oleh pemilik rumah kos.

4. Dimensi berikut adalah reliability yaitu memiliki pegawai yang dapat diandalkan dan menciptakan lingkungan yang terjaga kebersihannya. Dengan lingkungan yang bersih dan pegawai yang kon- sisten dalam membantu pengguna rumah kos di Siwalankerto kemudian dapat tetap merasa nyaman dan puas sehingga kepuasan tercipta dan intensi untuk berpindah juga menjadi rendah.

5. Dimensi terakhir yang harus diperhatikan adalah assurance yaitu memiliki keamanan yang terpercaya. Setiap rumah kos yang baik sebaiknya menciptakan rasa aman dan terpercaya seperti contoh meminimalkan barang yang hilang, dan menjaga keamanan keselurah rumah kos agar bebas maling.

6. Implikasi manajerial tersebut dapat terjadi penyedia jasa rumah perlu memberikan penyuluhan dan pelatihan informal kepada para pegawainya agar dapat memberikan pelayanan yang terbaik, khususnya dalam menangani dan menindaklanjuti keluhan para pengguna rumah kos. Apabila semua hal tersebut diperhatikan dan melakukan implikasi manajerial seperti di atas, maka disinyalir pengguna rumah kos akan merasa puas dan tingkat switching intention menurun.

Lebih lanjut, penelitian ini memiliki beberapa keterbatasan yaitu sebagai berikut:

1. Jumlah sampel yang kecil yaitu 155 responden di Siwalankerto tanpa membatasi karakteristik responden yang lain misalnya asal usul responden yang bisa memperkuat hipotesis dari sisi budaya dan norma-norma responden.

2. Pengukuran variabel kualitas layanan tidak didasarkan pada teori yang sangat kuat mengenai jasa rumah kos atau boarding house dan hanya berdasarkan arahan dimensi tangibility, emphaty, reliability, responsiveness, dan assurance.

3. Penelitian ini tidak mengungkapkan dimensi atau faktor dominan dalam mengukur variabel laten (kualitas layanan, kepuasan pelanggan dan switching intention).

4. Penelitian ini tidak menguji keseluruhan model PPM (push, pull, mooring factors) dari Bansal et.al. (2005) yang didalamnya terdapat beberapa hal yang perlu dikaji.

Berdasarkan keterbatasan-keterbatasan tersebut maka peneliti mengungkapkan saran untuk penelitian selanjutnya sebagai berikut:

1. Penelitian selanjutnya sebaiknya diuji pada ukuran sampel yang lebih besar agar benar-benar dapat digeneralisasikan dengan baik.

2. Penelitian selanjutnya juga diharapkan mengikutsertakan uji outer loadings yang lebih dispesifikasikan.

3. Oleh karena penelitian ini menghasilkan loading factor > 0.5 maka pada penelitian selanjutnya 
untuk sektor jasa khususnya rumah kos atau boarding house, indikator-indikatornya dapat digunakan.

4. Penelitian selanjutnya sebaiknya menggunakan beberapa faktor PPM yaitu untuk push selain kualitas dan kepuasan, yaitu nilai jasa yang rendah, kepercayaan yang rendah, komitmen pelanggan yang rendah, dan persepsi harga yang relatif tinggi. Selanjutnya untuk faktor pull yaitu ketertarikan terhadap penyedia jasa alternatif, sedangkan faktor mooring yaitu yaitu sikap tidak menguntungkan/mendukung perpindahan, norma subjektif yang tidak menguntungkan/mendukung perpindahan, biaya berpindah tinggi, perilaku berpindah dahulu/sebelumnya yang tidak sering, dan rendahnya kecenderungan pelanggan untuk mencari ragam/jenis lain.

\section{DAFTAR PUSTAKA}

Achmad, Nur, 2007, Analisis Simultan Kualitas Layanan terhadap Kepuasan Konsumen dan Minat Beli Pada Grapari Telkomsel di Surakarta. Jurnal Daya Saing. http://eprints.ums. ac.id/899/1/Jurnal_Daya_Saing_7_6

Bansal, Harvir, S., Shirley, F., Taylor, dan Yannik St. James, 2005, "Migrating to New Service Providers: Toward a Unifying Framework of Customers Switching Behaviors". Journal of The Academy of Marketing Science, Vol. 33, No.1.

Chin, W.W., 1998, The partial least square approach to structural equation modeling, in Marcoulides Ga (Ed), Modern methods for business research, Lawrence Erlbaum Associates, Mahwah, London, New Jersey, pp. 295-336.

Cooil, Bruce, Lerzan Aksoy, Timothy, L. \& Michael Hsu, January 2007, "A Longitudinal Analysis of Customer Satisfaction and Share of Wallet: Investigating the Moderating Effect of Customer Characteristics", Journal of Marketing, Vol. 71, pp. 67-83.

Fornell, C. dan Larcker, D., 1981, "Evaluating structural equation models with unobservable variables and measurement error", Journal of Marketing Research, vol. 19, pp. 440-452.

Ghozali, I., 2006, Structural Equation Medeling; Metode Alternatif dengan PLS. Badan Penerbit Undip. Semarang.

Hair, J.F., Jr. Anderson, R.E., Tatham, R.L. and Black, W.C., 1995, Multivariate Data Analysis, 3rd ed, Macmillan Publishing Company, New York.

Han, Sang-Lin dan Seung Baek, 2004, "Antecedents and Consequences of Service Quality in Online Banking: An Application of the
SERVQUAL Instrument". Advances in Consumer Research, Volume 31.

Haryanto. J. \& Chairy, 2007, "Model Baru Dalam Migrasi Pelanggan”. Jurnal Ekonomi dan Bisnis Fakultas Ekonomika dan Bisnis UKSW, Vol. XIII No.1.

http://www.petra.ac.id, diunduh pada tanggal 8 Agustus 2011.

http://www.surabaya.go.id, diunduh pada tanggal 8 Agustus 2011.

Ishak, Asmai, 2005, "Pentingnya Kepuasan Konsumen dan Implementasi Strategi Pemasarannya". Edisi Khusus Jurnal Siasat Bisnis on Marketing. ISSN 0853-7665.

Kim, M.M., Park, M.C., \& Jeong, D.H., 2004, The effects of customer satisfaction and switching barrier on customer loyalty in Korean mobile telecommunication services. Telecommunications Policy, 28(2), pp. 145-159.

Killa, Maklon F., 2010, Analisis Kualitas Layanan Rumah Sakit di Kota Waingapu. Journal of NTT Studies, 2(2), pp. 113-130.

Kotler, Philip, 1997, Manajemen Pemasaran: Analisis, Perencanaan, Implementasi dan Pengendalian. Edisi kedelapan, terjemahan Arcella Ariwati Hermawan. Jakarta: Salemba Empat.

Kotler, P., Hayes, Thomas, Bloom Paul, N., 2002, Marketing Professional Service. Prentice Hall International Press.

Krisdiana, Fike, 2007, Analisis Dimensi Kualitas Pelayanan Pada Hotel Saptra Mandala Blitar. eprints.umm.ac.id/7689/1/p.

Lovelock, Christopher dan Lauren Wright, 2007, Manajemen Pemasaran Jasa. Edisi kedua. PT. Indeks, Jakarta.

Malik, Muhammad Ehsan dan Basharat Naeem, 2011, Banking Clients' Perceived Service Quality and Behavioral Responses. European Journal of Social Sciences, Volume 23, Number 3

Mardalis, Ahmad, 2005, Meraih Loyalitas Pelanggan. http://eprints.ums.ac.id/238/1/benefit, Vol. 9, No. 2.

Musanto, Trisno, 2004, "Faktor-Faktor Kepuasan Pelanggan dan Loyalitas Pelanggan: Studi Kasus pada CV. Sarana Media Advertising Surabaya". Jurnal Manajemen \& Kewirausahaan, Vol.6, No.2, pp. 123-136.

Nugroho, Adi, 2010, "Menumbuhkan Service Loyalty Melalui Kualitas Pelayanan dan Pengelolaan Respon Emosi Konsumen Pada Perusahaan Jasa". Jurnal Manajemen.

Oliver. R.L., 1999, "Whence consumer loyalty", Journal of Marketing, 63 (special issue), pp. 33-44.

Parasuraman, A., Zeithaml, V. dan Berry, L., 1988, "SERVQUAL: An multiple item Scale for Measuring Consumers Perceptions of Service 
Quality”. Journal of Retailing. Vol. 64 No. 1.

Roostika, Ratna, 2011, The Effect of Perceived Service Quality and Trust on Loyalty: Customer's Perspectives on Mobile Internet Adoption. International Journal of Innovation, Management and Technology, Vol. 2, No. 4.

Schiffman, L.G. dan Kanuk, L.L., 2010, Consumer Behavior. Edisi ke 10. Prentice-Hall International, Inc., Upper Saddle River, New Jersey.

Sekaran, Uma, 2003, Research Method for Business. Fourth Edition. John Willey \& Sons, Inc., 111 River Street, Hoboken, New Jersey.

Setiyaningrum, Ari, 2007, "Pengaruh Ketidakpuasan Konsumen dan Variety Seeking terhadap Keputusan Perpindahan Merek". Telaah Manajemen, Vol. 2, No. 2.

Sugiyono, 2010, Metode Penelitian Kuantitatif Kualitatif dan $R \& D$, Alfabeta $C V$ Bandung.

Supramono dan Haryanto, O.J., 2005, Desain Proposal Penelitian Studi Pemasaran. Penerbit Andi Yogyakarta.

Szymanski, D.M. \& Henard, D.H., 2001, Customer satisfaction: A meta-analysis of the empirical evidence. Journal of the Academy of Marketing Science, 29(1), 16-35.
Tjiptono, Fandy, 1997, Strategy Pemasaran, Penerbit: Andi offset. Edisi Kedua, Cetakan Pertama, Yogyakarta.

Vlachos, P.A. dan Vrechopoulos, P.A., 2008, Determinants of behavioral intentions in the mobile internet services market, Journal of Services Marketing, Vol. 2, No. 4, pp. 280-291.

Widiawan, K. dan Irianty, 2005, Pemetaan Preferensi Konsumen Supermarket dengan Metode Kano Berdasarkan Dimensi SERVQUAL. Jurnal Teknik Industri, Vol. 6, No.1.

Wijanto, S.H., 2008, Structural Equation Modelling dengan Lisrel 8.8, Konsep dan Tutorial. Edisi Pertama. Penerbit Graha Ilmu Yogyakarta.

Wijaya, Tony, 2009, Analisis Structural Equation Modeling menggunakan AMOS. Universitas Atma Jaya, Yogyakarta.

Yuliana dan Mustikawati, 2007, Analisis Pengaruh Dimensi Kualitas Jasa pada Loyalitas Pelanggan (Studi Kasus pada Jasa Bengkel Sepeda Motor Yogyakarta). Jurnal Ekonomi dan Manajemen, Vol. 8, No. 2. 